\title{
Oligofructose contributes to the protective role of bifidobacteria in experimental necrotising enterocolitis in quails
}

\author{
I. CATALA, M. J. BUtel*, M. BEnSAAdA, F. POPOT, A. C. TESSEdRE*, A. RIMBAULT* and \\ O. SZYLIT
}

Unité d'Ecologie et Physiologie du Système Digestif, Equipe Métabolites Bactériens et Santé, Institut National de la Recherche Agronomique, Jouy-en-Josas and *Faculté des Sciences Pharmaceutiques et Biologiques, Laboratoire de Microbiologie, Unité Microbiologie Anaérobie, Université René Descartes, Paris, France

\begin{abstract}
Bifidobacteria are dominant in the gut of full-term infants, although colonisation by them is often delayed in preterm neonates. Bifidobacteria are recognised to have beneficial effects on digestive disorders and they might prevent neonatal necrotising enterocolitis (NEC), a gastrointestinal disease that predominantly affects premature infants. They have been shown to protect gnotobiotic quails against NEC-like lesions when the birds were inoculated with faecal flora from preterm infants, decreasing the clostridial population. The present study was designed to investigate whether oligofructose, which stimulates the activity of bifidobacteria, may enhance their protective role. Experiments were done in eight groups of germ-free quails for 28 days. The groups differed as to their bacterial status, diet and environment. Quails were inoculated with one of two flora from premature twins. The first flora included Bifidobacterium pseudo-catenulatum, Escherichia coli and no clostridia. The second flora included clostridial species and was associated with $B$. infantis-longum. Caecal bacterial population and metabolism changes were investigated with a lactose $(6 \%)$ diet versus a lactose-oligofructose (3\%-3\%) diet, either in a gnotobiotic environment or in an ordinary environment permitting post-colonisation by exogenous bacteria. In both environments and with both flora, oligofructose significantly increased the level of bifidobacteria and this was associated with a decrease of $E$. coli or $C$. perfringens and $C$. ramosum. The bacterial changes in the ordinary environment depended on the initial composition of the microflora and the colonisation resistance against exogenous bacteria was more efficient with the flora that included $B$. pseudo-catenulatum. The changes in caecal $\mathrm{pH}$ and short-chain fatty acids were minimal. It was demonstrated that, irrespective of the environmental conditions, the use of oligofructose helped to prevent the overgrowth of bacteria implicated in necrotising enterocolitis in preterm neonates.
\end{abstract}

\section{Introduction}

Necrotising enterocolitis (NEC) is one of the most common serious gastrointestinal diseases in neonatal intensive care units; it causes significant mortality and severe chronic morbidity after resection of necrotic bowel [1]. To date, none of the preventive treatments, i.e., antibiotic therapy, prophylactic treatment and parenteral feeding, is considered fully satisfactory.

Received 3 Dec. 1997; revised version accepted 30 April 1998.

Corresponding author: Dr M. J. Butel.
In adults, prophylactic treatments that manipulate the autochtonous microflora with non-digestible oligosaccharides as a means of preventing digestive disorders have aroused interest for many years. Among these oligosaccharides, oligofructose (OF) has been demonstrated to be capable of increasing the numbers of Bifidobacterium spp. [2,3] which are considered to be the best candidates for exerting biological activity promoting health $[3,4]$. Clinical attempts to establish bowel colonisation with bifidobacteria showed that exogenous bifidobacteria were maintained only when fermented dairy products were consumed [5]. In healthy full-term babies fed breast milk, bifidobacterial colonisation of the gut appears in 
the first days of life and predominates at 2 weeks of age [6-9]. In contrast, this colonisation is often delayed for 2-3 weeks in preterm infants [6-8], thus favouring high levels of Clostridium spp., e.g., $C$. butyricum, $C$. perfringens and $C$. paraputrificum, implicated in the aetiology of NEC [10-14]. In a pair of premature twins, it was observed that at 3 days old the stools of one twin contained mainly bifidobacteria, whereas no bifidobacteria but high levels of clostridia, including $C$. butyricum and $C$. perfringens, were found in the second. The neonate harbouring bifidobacteria remained healthy while the other developed NEC [15].

Human breast milk has many specific and non-specific components thought to protect against potentially pathogenic bacteria. Among them, the oligosaccharide fraction is considered to be beneficial in full-term infants $[16,17]$, but has never been investigated in preterm neonates.

In order to study the pathogenesis and the prevention of NEC, gnotobiotic alactasic models, i.e., chicken and quail species which do not possess intestinal lactase, were developed in which caecitis associated with Clostridium spp. occurred [18-20]. The association of germ-free quails with the whole faecal flora from the premature twins demonstrated that bifidobacteria when initially present in the faecal flora or administered early prevented caecitis through the inhibition of clostridial species [15].

The aim of the present study was to investigate, with the gnotobiotic model, whether OF plays a protective role additional to that of bifidobacteria in a gnotobiotic environment and in an ordinary environment permitting post-colonisation by exogenous bacteria, as gut colonisation varies in preterm babies in neonatal intensive care units.

\section{Materials and methods}

\section{Faecal flora from premature twin neonates}

The two faecal flora came from premature dizygotic twins born at a gestational age of 33 weeks at the Centre de Pédiatrie Gatien de Clocheville, Tours. No antibiotic treatment was given at birth and enteral feeding started on day 2 with breast milk. One twin remained healthy, the other twin developed NEC; stool samples were collected from both twins a few hours before the onset of the disease. Both flora contained enterococci $\left(\log _{10} 3.7\right.$ and $8.6 / \mathrm{g}$ of faeces, respectively) as described previously [15]. In the flora of the healthy twin, $E$. coli was present $\left(\log _{10} 10.2 / \mathrm{g}\right)$, clostridia were not detected and a high level of bifidobacteria was found $\left(\log _{10} 8.9 / \mathrm{g}\right)$. The bifidobacteria were identified as either $B$. catenulatum or $B$. pseudo-catenulatum on the basis of phenotypic characters (biochemical and enzymic characters;
bioMérieux API, F-69280 Marcy l'Etoile, France). The numerical identification system developed by $F$. Gavini (personal communication) identified the isolates as $B$. pseudo-catenulatum. In the flora of the sick twin, the major differences observed with the healthy flora were the presence of two clostridial species $-C$. difficile $\left(\log _{10} 5.4 / \mathrm{g}\right)$ and $C$. perfringens $\left(\log _{10} 3.8 / \mathrm{g}\right)$. E. coli was not present, although Proteus mirabilis was detected $\left(\log _{10} 8.0 / \mathrm{g}\right)$. For the purpose of the study, this flora was associated with a $B$. infantislongum strain isolated from the stool of a healthy premature infant (strain CUETM 89-215, collection of the Unité d'Ecotoxicologie Médicale, INRA, Villeneuve d'Ascq).

The two flora were referred to as healthy flora and NEC-bif flora, respectively.

\section{Diets}

Two experimental semi-synthetic diets were compared in quails. One diet (already described [19]) contained lactose $6 \% \mathrm{w} / \mathrm{w}$ to mimic the proportion of lactose in milk. The other was a similar diet where half the lactose $(3 \% \mathrm{w} / \mathrm{w})$ was replaced by OF $3 \% \mathrm{w} / \mathrm{w}$. OF was the oligosaccharide fraction of Raftilose (Orafti, Tienen, Belgium). It is composed of molecules of GFn and Fn type (G, glucose; F, fructose; $n$, number of fructose moieties linked by $\beta[2,1]$ linkages in a ratio of c. 2:1), with $\mathrm{n}$ being $2-6$, with an average polymerisation degree of 4 . The diet was sterilised by gamma irradiation at $40 \mathrm{kGy}$. Diets were referred to as lactose diet and lactose/OF diet, respectively.

\section{Experimental design}

Maintenance and inoculation of quails. Germ-free quails (Coturnix coturnix subsp. japonica) were obtained by the method of Reynier and Sackteder [21] with the modifications described by Bousseboua et al. [19]. Two-week-old germ-free quails fed a nonlactose diet were transferred to various experimental germ-free isolators. The germ-free status of quails was checked before bacterial inoculation. Quails were inoculated orally with $100 \mu \mathrm{l}$ of cultures containing $10^{8}$ viable cells of the bifidobacterial strain or a 10 -fold dilution of the faecal flora, or both. Bacterial establishment was checked by examining fresh droppings at weekly intervals.

Experiment 1. Germ-free quails were separated into four isolators that provide absolute control of air-borne infection and prevent contact from exogenous organisms. The experimental groups consisted of gnotobiotic quails inoculated with either the healthy flora (group I) or the NEC-Bif flora (group II). Quails in each group were divided into two subgroups and fed with either the lactose diet (group $\mathrm{I}_{\mathrm{L}}, 11$ quails and group $\mathrm{II}_{\mathrm{L}}, 8$ quails) or the lactose/OF diet (groups $\mathrm{I}_{\mathrm{OF}}, 11$ quails and $\mathrm{II}_{\mathrm{OF}}, 9$ quails) (Table 1 ). 
Table 1. Characteristics of groups of germ-free quails inoculated with healthy flora or NEC-Bif flora

\begin{tabular}{|c|c|c|c|c|}
\hline Groups of quails & Number of quails & Diet & Inoculum & Environmental status \\
\hline $\begin{array}{l}\mathrm{I}_{\mathrm{L}} \\
\mathrm{I}_{\mathrm{OF}} \\
\mathrm{II}_{\mathrm{L}} \\
\mathrm{II}_{\mathrm{OF}} \\
\mathrm{III}_{\mathrm{L}} \\
\mathrm{III}_{\mathrm{OF}} \\
\mathrm{IV}_{\mathrm{L}} \\
\mathrm{IV}_{\mathrm{OF}}\end{array}$ & $\begin{array}{r}11 \\
11 \\
8 \\
9 \\
12 \\
12 \\
9 \\
8\end{array}$ & $\begin{array}{l}\text { Lactose } \\
\text { Lactose/OF } \\
\text { Lactose } \\
\text { Lactose/OF } \\
\text { Lactose } \\
\text { Lactose/OF } \\
\text { Lactose } \\
\text { Lactose/OF }\end{array}$ & $\begin{array}{l}\text { Healthy flora* } \\
\text { Healthy flora* } \\
\text { NEC-Bif flora } \\
\text { NEC-Bif flora } \\
\text { Healthy flora* } \\
\text { Healthy flora* } \\
\text { NEC-Bif flora } \\
\text { NEC-Bif flora }\end{array}$ & $\begin{array}{l}\text { Gnotobiotic } \\
\text { Gnotobiotic } \\
\text { Gnotobiotic } \\
\text { Gnotobiotic } \\
\text { Ordinary }^{\ddagger} \\
\text { Ordinary }^{\ddagger} \\
\text { Ordinary } \\
\text { Ordinary } \\
\text { Or }^{\ddagger}\end{array}$ \\
\hline
\end{tabular}

${ }^{*}$ B. pseudo-catenulatum (bifidobacterium resident).

${ }^{\dagger}$ B. infantis-longum CUETM 89-215 (bifidobacterium added).

${ }^{\ddagger}$ Air filters of the isolators were removed to enable further infection by bacteria from the external environment.

Experiment 2. As in experiment 1, quails were separated into four isolators and inoculated with the healthy flora (group III) and the NEC-Bif flora (group IV). One week after inoculation the establishment of bacteria in their gut was checked. The air filters of the isolators were then removed to enable further infection by bacteria from the external environment. This was defined as ordinary environment. Then, quails of each group were divided into two subgroups and fed either the lactose diet (group $\mathrm{III}_{\mathrm{L}}, 12$ quails and group $\mathrm{IV}_{\mathrm{L}} 9$ quails) or the lactose/OF diet (group $\mathrm{III}_{\mathrm{OF}}, 12$ quails and group $\mathrm{IV}_{\mathrm{OF}}, 8$ quails) (Table 1 ).

\section{Sampling, bacterial counts and biochemical determinations}

The quails were killed 28 days after inoculation. Caeca were collected immediately after death and the contents were removed for $\mathrm{pH}$ measurement, bacteriological and biochemical determinations. The weight of the caecal wall was expressed as the caecal wall weight to body weight ratio. Caeca were characterised macroscopically as normal $(\mathrm{N})$, thickened $(\mathrm{T})$, showing pneumatosis $(\mathrm{P})$ and having haemorrhagic contents $(\mathrm{H})$. Quails were considered as healthy when none of the three last criteria was observed.

Aerobic and anaerobic bacterial species were counted as described previously. Briefly, serial dilutions of the caecal contents were spread on various media allowing the enumeration of bifidobacteria, clostridia, Bacteroides spp., Enterobacteriaceae, enterococci and staphylococci [15]. Isolates were identified by standard laboratory methods. Bacterial counts were expressed as $\log _{10}$ numbers (cfu/g of caecal content). The count threshold was $10^{3} \mathrm{cfu} / \mathrm{g}$ caecal content. Short-chain fatty acid (SCFA) concentrations were determined by gas chromatography as described previously [22].

\section{Statistical analysis}

Data are presented as the mean and SEM. Statistical significance was considered at $p<0.05$. Analysis of variance followed by Fisher's test was used when comparing the two diets (lactose versus lactose/OF).

\section{Results}

None of the quails was sick in the presence of bifidobacteria irrespective of the presence or absence of OF and the two different environmental conditions.

\section{Experiment 1: influence of diet in the gnotobiotic environment}

Compared with the lactose diet, the lactose/OF diet significantly increased the bifidobacterial numbers whatever the origin of the strain (resident in the healthy flora or added in the NEC-Bif flora) (Table 2). In the healthy flora (groups $\mathrm{I}_{\mathrm{L}}$ and $\mathrm{I}_{\mathrm{OF}}$ ) there was a significant decrease in the numbers of $E$. coli. In the NEC-Bif flora (groups $\mathrm{II}_{\mathrm{L}}$ and $\mathrm{II}_{\mathrm{OF}}$ ) C. perfringens was no longer detected, the $C$. difficile count did not alter and the number of $P$. mirabilis decreased slightly. The numbers of enterococci were not modified in either flora.

The mean caecal wall weight to body weight ratio ranged from 3.7 to 4.2 whatever the flora and the diet (Table 3 ). In the healthy flora the introduction of OF in the diet led to a slight $\mathrm{pH}$ increase, but the SCFA concentrations were unaltered. In the NEC flora, $\mathrm{pH}$ was unchanged; SCFA concentrations decreased, but not significantly. For both flora, SCFA profiles mainly comprised acetate and the introduction of OF increased the proportion of isobutyrate, butyrate, isovalerate and valerate.

\section{Experiment 2: influence of the diet in the ordinary environment}

The lactose/OF diet significantly increased the bifidobacterial numbers in both groups. With the healthy flora the other bacterial numbers were not modified. In the NEC-bif flora OF significantly decreased the number of $E$. coli, $C$. perfringens and $C$. ramosum (Table 2). C. difficile decreased, but not significantly.

OF did not affect the caecal wall weight to body weight ratio, $\mathrm{pH}$ or SCFA concentrations, although slight modifications of butyrate ratio occurred with both flora (Table 3 ). 

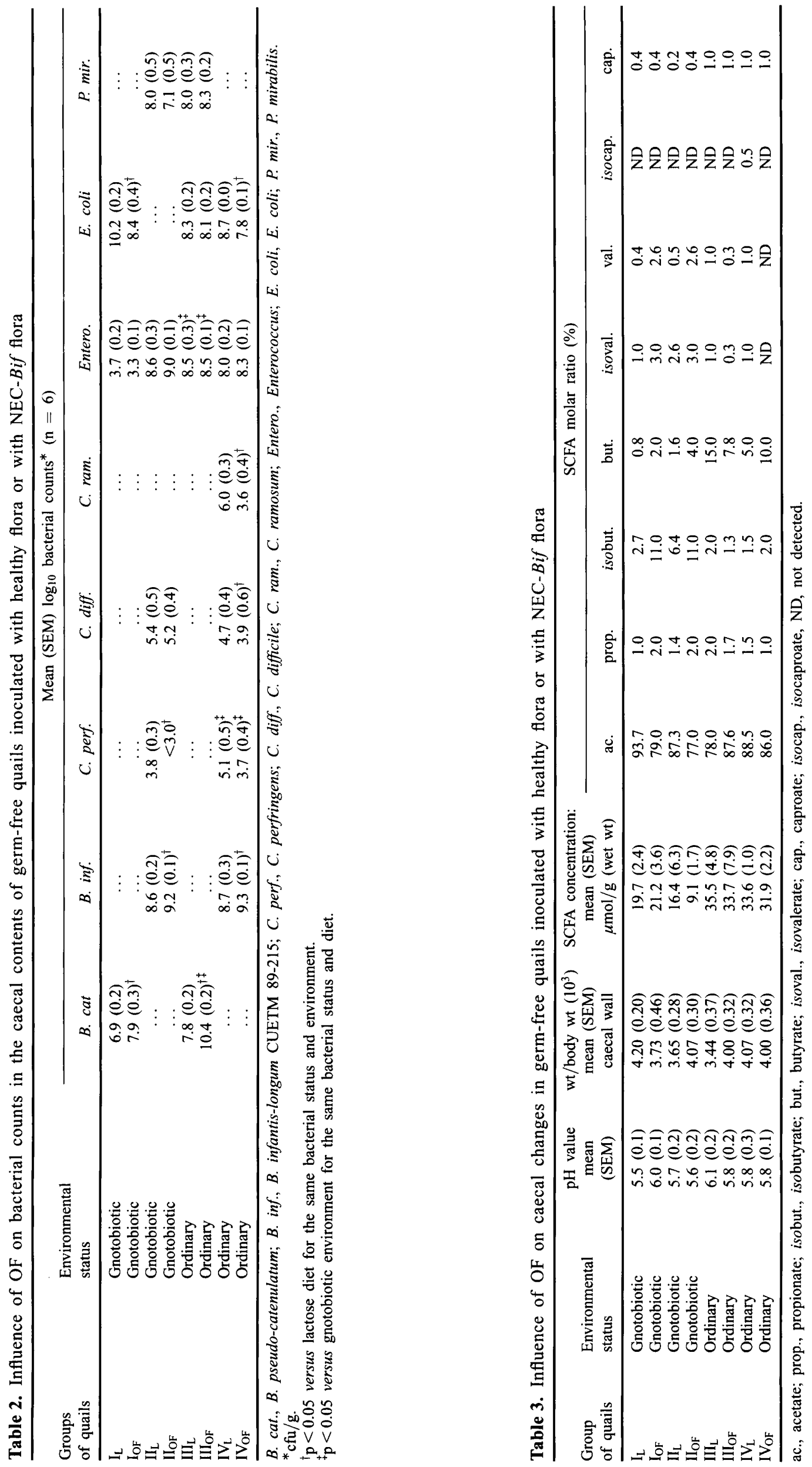
Comparison of the gnotobiotic and ordinary environments

The intestinal microflora was altered qualitatively and quantitatively by the external environment. In the healthy flora, $P$. mirabilis appeared and the number of enterococci increased $\left(\log _{10} 8.5\right.$ in group III versus $c$. 3.5 in group I). In the NEC-Bif flora, C. ramosum and $E$. coli were acquired and $P$. mirabilis disappeared. The increase in the level of B. pseudo-catenulatum caused by the addition of OF was significantly greater in the ordinary environment than in the gnotobiotic environment $\left(+2.6 \log _{10}\right.$ in group III versus $+1 \log _{10}$ in group I). In contrast, with NEC-Bif flora no difference was observed in $B$. infantis-longum numbers and $C$. perfringens counts were higher in the ordinary environment.

There were no significant differences in $\mathrm{pH}$ and caecal wall weight to body weight ratios. Whatever the diet, total SCFA concentrations were higher in quails kept in the ordinary environment (c. $33 \mu \mathrm{mol} / \mathrm{g}$ in groups III and IV versus $9.1-21.2 \mu \mathrm{mol} / \mathrm{g}$ in groups I and II). The proportion of butyrate was increased at the expense of isobutyrate.

\section{Discussion}

Clostridium spp. and $E$, coli are known to be responsible for NEC in preterm infants [23-27]. The present study showed how OF may participate in the health-promoting effect of bifidobacteria against NEClike lesions in quails. In both environments studied, OF increased the numbers of bifidobacteria. With the healthy flora ( $B$. pseudo-catenulatum, resident) the increase in bifidobacterial count was associated with a decrease of $E$. coli. In the NEC-B.inf flora groups ( $B$. infantis-longum, added) the increase in the count of bifidobacteria was associated with strongly decreased numbers of $C$. perfringens and $C$. ramosum. These results were in agreement with both in-vitro [28, 29] and in-vivo [2] studies showing that OF favours the growth of bifidobacteria and inhibits the growth of clostridia and $E$. coli. However, $C$. difficile was unaffected by the increase of bifidobacteria. Its role in NEC is controversial. In rare cases, $C$. difficile toxins have been found in the faeces of infants with NEC [24]; no relationship has been found between the acquisition or the carriage of toxigenic $C$. difficile and intestinal symptoms [30].

The normal acquisition of flora is altered in preterm neonates by the prolonged stay in intensive care units associated with an increased risk of nosocomial infection. The ordinary environment investigated in this study simulated the conditions where infants are exposed to potentially pathogenic bacteria. Qualitative and quantitative changes were observed in the gut colonisation of the quails. With the healthy flora, $P$. mirabilis, usually found in preterm infants, was acquired from the external environment, but no clostridia were detected. In the NEC-bif flora the number of $C$. perfringens was higher than in the gnotobiotic environment and $C$. ramosum was acquired. C. ramosum has been linked to various infections in children [31], but was not usually observed in the faecal bacterial population of neonates. This new bacterial composition is close to those found in neonatal intensive care units where Enterobacteriaceae (E. coli, Klebsiella spp., Proteus spp.) and enterococci are detected at a high level up to $\log _{10} 10 / \mathrm{g}$ of stool, clostridia are detected at $\log _{10}$ $5-8 / \mathrm{g}$ of stool depending on the species and bifidobacteria at $\log _{10} 0-10 / \mathrm{g}$ of stool in faecal specimens from healthy preterm neonates $[6-9,25]$.

The changes in the microflora observed depended on the composition of the initial microflora. The colonisation resistance against clostridial species appeared more efficient with flora containing $B$. pseudocatenulatum than with flora containing $B$. infantislongum. The numbers of the two different Bifidobacterium spp. did not explain this difference. This effect might be related to the bifidobacterial species; B. pseudo-catenulatum occurs at higher level than other bifidobacterial species but at a low frequency in breast-fed infants [9]. On the other hand, in-vitro fermentation experiments suggested that Bifidobacterium spp. differ in their responsiveness to protein and oligosaccharide growth promoters $[32,33]$.

Bifidogenic properties of OF were demonstrated whatever the flora, but their differences depended on the initial composition and were, therefore, more marked with the healthy flora. OF participate in the health promoting effect of bifidobacteria by exerting a beneficial effect on microflora balance, but not on the bacterial metabolites tested. The mechanism by which OF played a health-promoting role is still under discussion and has often been associated with fermentation of $\mathrm{OF}$ by bifidobacteria which subsequently led to a $\mathrm{pH}$ decrease $[28,29]$. In the present study $\mathrm{pH}$ values did not differ statistically whatever the microflora and total SCFA concentrations were not linked to the presence of OF in the diet. Only slight changes in caecal SCFA profiles were observed.

Clinical trials of colonisation of the immature bowel of preterm infants with probiotics (Lactobacillus GG, $B$. breve) have shown that they need to be administered regularly (once or twice a day) [34-36]. In the present study, the daily intake of OF contributed to long-term colonisation with bifidobacteria at a high level after a single early administration of the probiotic and reduced colonisation by potentially pathogenic bacteria. These findings illustrated the potential application of the concept of synbiotics proposed by Gibson and Roberfroid as the combination of probiotics and prebiotics [3]. As an alternative to antibiotic therapy or to prophylactic treatments, an 
early administration of probiotics associated with a nutritional programme including the use of OF could be a promising approach to the prevention of NEC.

We are very grateful to Orafti, Tienen, Belgium, for supporting this study and to Dr F. Gavini, Laboratoire de Génie des Procédés et Technologie Alimentaires, INRA, Villeneuve d'Ascq, France for providing the $B$. infantis-longum strain and identifying $B$. pseudocatenulatum strains. We thank Drs J.C. Borderon and A. Favre of the Service de Médecine Néonatale, Centre de Pédiatrie Gatien de Clocheville, Tours, for the faecal flora from preterm neonates.

\section{References}

1. Kliegman RM, Fanaroff AA. Necrotizing enterocolitis. $N$ Engl $J$ Med 1984; 310: 1093-1103.

2. Gibson GR, Beatty ER, Wang X, Cummings JH. Selective stimulation of bifidobacteria in the human colon by oligofructose and inulin. Gastroenterology 1995; 108: 975-982.

3. Gibson GR, Roberfroid MB. Dietary modulation of the human colonic microbiota: introducing the concept of prebiotics. J Nutr 1995; 125: 1401-1412.

4. Fuller R. Probiotics in human medicine. Gut 1991; 32: 439-442.

5. Bouhnik Y, Pochart P, Marteau P, Arlet G, Goderel I, Rambaud JC. Fecal recovery in humans of viable Bifidobacterium $\mathrm{sp}$ ingested in fermented milk. Gastroenterology 1992; 102: 875-878.

6. Stark PL, Lee A. The bacterial colonization of the large bowel of pre-term low birth weight neonates. J Hyg 1982; 89: 59-67.

7. Sakata H, Yoshioka H, Fujita K. Development of the intestinal flora in very low birth weight infants compared to normal fullterm newborns. Eur $J$ Pediatr 1985; 144: 186-190.

8. Hall MA, Cole CB, Smith SL, Fuller R, Rolles CJ. Factors influencing the presence of faecal lactobacilli in early infancy. Arch Dis Child 1990; 65: 185-188.

9. Kleessen B, Bunke H, Tovar K, Noack J, Sawatzki G. Influence of two infant formulas and human milk on the development of the faecal flora in newborn infants. Acta Paediatr 1995; 84: 1347-1356.

10. Howard FM, Bradley JM, Flynn DM, Noone P, Szawatkowski M. Outbreak of necrotising enterocolitis caused by Clostridium butyricum. Lancet 1977; 2: 1099-1102.

11. Gothefors L, Blenkharn I. Clostridium butyricum and necrotising enterocolitis. Lancet 1978; 1: 52-53.

12. Laverdire $M$, Robert A, Chicoine R, Salet D, Rosenfeld R. Clostridia in necrotising enterocolitis. Lancet 1978; 2: 377.

13. Kelsey MC, Vince AJ. Clostridia in neonatal faeces. Lancet 1979; 2: 100 .

14. Lawrence G, Bates J, Gaul A. Pathogenesis of neonatal necrotising enterocolitis. Lancet 1982; 1: 137-139.

15. Butel MJ, Roland N, Hibert A et al. Clostridial pathogenicity in experimental necrotising enterocolitis in gnotobiotic quails and protective role of bifidobacteria. J Med Microbiol 1998; 47: 391-399.

16. Horton BS. Commercial utilization of minor milk components in the health and food industries. $J$ Dairy Sci 1995; 78: 2584-2589.

17. Newburg DS. Do the binding properties of oligosaccharides in milk protect human infants from gastrointestinal bacteria? $J$ Nutr 1997; 127(Suppl): 980S-984S.

18. Popoff MR, Szylit O, Ravisse P, Dabard J, Ohayon H. Experimental cecitis in gnotoxenic chickens monoassociated with Clostridium butyricum strains isolated from patients with neonatal necrotizing enterocolitis. Infect Immun 1985; 47: 697-703.

19. Bousseboua H, Le Coz Y, Dabard J et al. Experimental cecitis in gnotobiotic quails monoassociated with Clostridium butyricum strains isolated from patients with neonatal necrotizing enterocolitis and from healthy newborns. Infect Immun 1989; 57: $932-936$.

20. Szylit O, Butel M-J, Rimbault A. An experimental model of necrotising enterocolitis. Lancet 1997; 350: 33-34.

21. Reyniers JA, Sacksteder MR. Raising Japanese quail under germfree and conventional conditions and their use in cancer research. $J$ Natl Cancer Inst 1960; 24: 1405-1416.

22. Guérin-Danan C, Andrieux C, Popot F et al. Pattern of metabolism and composition of the fecal microflora in infants 10 to 18 months old from day care centers. $J$ Pediatr Gastroenterol Nutr 1997; 25: 281-289.

23. Kliegman RM, Fanaroff AA, Izant R, Speck WT. Clostridia as pathogens in neonatal necrotizing enterocolitis. J Pediatr 1979; 95: 287-289.

24. Cashore WJ, Peter G, Lauermann M, Stonestreet BS, Oh W. Clostridia colonization and clostridial toxin in neonatal necrotizing enterocolitis. $J$ Pediatr 1981; 98: 308-311.

25. Blakey JL, Lubitz L, Campbell NT, Gillam GL, Bishop RF, Barnes GL. Enteric colonization in sporadic neonatal necrotizing enterocolitis. $J$ Pediatr Gastroenterol Nutr 1985; 4: 591-595.

26. Kosloske AM. Epidemiology of necrotizing enterocolitis. Acta Paediatr Suppl 1994; 396: 2-7.

27. Speer ME, Taber LH, Yow MD, Rudolph AJ, Urteaga J, Waller S. Fulminant neonatal sepsis and necrotizing enterocolitis associated with a "nonenteropathogenic" strain of Escherichia coli. J Pediatr 1976; 89: 91-95.

28. Wang $\mathrm{X}$, Gibson GR. Effects of the in vitro fermentation of oligofructose and inulin by bacteria growing in the human in the large intestine. J Appl Bacteriol 1993; 75: 373-380.

29. Gibson GR, Wang X. Enrichment of bifidobacteria from human gut contents by oligofructose using continuous culture. FEMS Microbiol Lett 1994; 118: 121-128.

30. Delmée M, Verellen V, Avesani V, François G. Clostridium difficile in neonates: serogrouping and epidemiology. Eur $J$ Pediatr 1988; 147: 36-40.

31. Brook I. Clostridial infection in children. $J$ Med Microbiol 1995; 42: 78-82.

32. Mitsuoka T, Hidaka H, Eida T. Effect of fructo-oligosaccharides on intestinal microflora. Nahrung 1987; 31: 427-436.

33. Petschow BW, Talbott RD. Response of bifidobacterium species to growth promoters in human and cow milk. Pediatr Res 1991; 29: 208-213

34. Millar MR, Bacon C, Smith SL, Walker V, Hall MA. Enteral feeding of premature infants with Lactobacillus GG. Arch Dis Child 1993; 69: 483-487.

35. Kitajima H, Sumida Y, Tanaka R, Yuki N, Takayama H, Fujimura M. Early administration of Bifidobacterium breve to preterm infants: randomised controlled trial. Arch Dis Child Fetal Neonatal Ed 1997; 76: F101-F107.

36. Grönlund MM, Lehtonen OP, Kero P, Saxelin M, Salminen S. Lactobacillus GG supplementation does not reduce faecal colonization of Klebsiella oxytoca in preterm infants. Acta Paediatr 1997; 86: 785-786. 